\title{
The effect of platelet-rich plasma in bone-tendon integration
}

\author{
İsmail Ağır ${ }^{1}, A, B, D-F$, Mahmut Nedim Aytekin², A, B, D, Fatih Küçükdurmaz ${ }^{2}, A, C, D$, Barış Kocaoğlü, A, E, F, \\ Sule Çetinel ${ }^{4, B}$, Mustafa Karahan ${ }^{3, A, E, F}$ \\ ${ }^{1}$ Faculty of Medicine, Adiyaman University, Adıyaman, Turkey \\ ${ }^{2}$ Department of Orthopedics and Traumatology, Yildırım Beyazıt University, Ankara, Turkey \\ ${ }^{3}$ Department of Orthopedics and Traumatology, Faculty of Medicine, Acibadem University, İ stanbul, Turkey \\ ${ }^{4}$ Department of Histology and Embryology, Faculty of Medicine, Marmara University, İstanbul, Turkey \\ A - research concept and design; $\mathrm{B}$ - collection and/or assembly of data; $\mathrm{C}$ - data analysis and interpretation; \\ $D$ - writing the article; $E$ - critical revision of the article; $F$ - final approval of article
}

\section{Address for correspondence \\ Ismail Ağır}

E-mail: iagir@hotmail.com

\section{Funding sources \\ none declared}

\section{Conflict of interest}

none declared

Received on June 28, 2015

Revised on August 12, 2015

Accepted on January 14, 2016

DOI

$10.17219 /$ acem/61384

\section{Copyright}

Copyright by Author(s)

This is an article distributed under the terms of the

Creative Commons Attribution Non-Commercial License

(http://creativecommons.org/licenses/by-nc-nd/4.0/)

\begin{abstract}
Background. The operative reconstruction of a torn or insufficient anterior cruciate ligament has become a routine surgical procedure in orthopedics. The long-term success of an anterior cruciate ligament reconstruction depends on the ability of the graft to heal adequately in a bone tunnel. Investigators studying reconstructions described healing within a tunnel as osseous ingrowth and incorporation. In particular, helping the healing using autologous material for the best integration process was a new idea that helped us to set up this study.

Objectives. The purpose of this study is to show the effect of platelet-rich plasma on bone-tendon healing.

Material and methods. Ten New Zealand rabbits were used. The study had 2 groups: (1) a study group including the right extremities of rabbits in which tendon-bone integration was strengthened by plateletrich plasma and (2) a control group including the left extremities of rabbits in which tendon-bone integration was without platelet-rich plasma. On the $56^{\text {th }}$ day postoperatively, the portion of the distal femur containing the tunnel was amputated following the euthanization process for histological evaluation.

Results. In the histological evaluation of the tendon-integrated bone segments with platelet-rich plasma, the integration of tendon in the bone was successful without any necrosis formation in most of the tissues. However, in the control group without platelet-rich plasma, the integration was distorted in many zones and some cystic morphologies were present.

Conclusions. The findings of this study showed that using platelet-rich plasma during tendon-to-bone implantation has positive effects histologically. In the literature, many studies are available that have investigated the effect of platelet-rich plasma on anterior cruciate surgery radiologically. However, the histological findings are more reliable than radiological findings because bone-tendon integration is a biological process.
\end{abstract}

Key words: platelet-rich plasma, anterior cruciate ligament, tendon, integration, revision surgery 
Lesions of the anterior cruciate ligament (ACL) represent one of the most common traumas in sporting practice and have shown a tendency to increase in the last few years. ${ }^{1}$ Operative reconstruction of a torn or insufficient ACL has become a routine surgical procedure in orthopedics. ${ }^{2}$ The most commonly used grafts for this procedure are autologous bone-patellar tendon-bone, hamstring, and quadriceps tendons. Biomechanical testing has shown that the initial strength of the graft materials is higher than that of the intact ACL. ${ }^{3}$ Hence, the most fragile linkage between the 2 tissues is the femoral and tibial fixation points rather than the graft itself. ${ }^{4}$ This finding has led to the commercial development of certain fixation materials. These materials are functional only before tissue healing occurs. Ultimately, the long-term success of an ACL reconstruction depends on the ability of the graft to heal adequately in a bone tunnel.

Researchers studying reconstructions have described healing within a tunnel as osseous ingrowth and incorporation in the surrounding tissue and then toward the tendon tissue. ${ }^{5}$ Healing using autologous material for the best integration process was the idea that initiated this study. ${ }^{6}$

In 1990, Gibble and Ness introduced fibrin glue, alternatively referred to as fibrin sealant or fibrin gel, a biomaterial that was developed in response to the necessity for improved hemostatic agents with adhesive properties. ${ }^{7}$

Platelet-rich plasma (PRP) gel is an autologous modification of fibrin glue that has been described and used in various applications with apparent clinical success. ${ }^{8}$ PRP obtained from autologous blood is used to deliver growth factors in high concentrations to the site of the bone defect or a region requiring augmentation. ${ }^{9}$

Late union of the graft and tunnel expansion due to repeated movement is a significant problem associated with primary and revision ACL surgery. It is believed that the PRP improves the integration between the bone and the graft.

\section{Material and methods}

A total of 10 New Zealand rabbits, weighing 3000$-3500 \mathrm{~g}$, were used. The study was comprised of 2 groups: A study group including the right extremities of the rabbits (10 right knees) in which bone-tendon integration was strengthened using PRP; and a control group including the left extremities of the rabbits (10 left knees) in which bone-tendon integration was performed without PRP. The Research Ethics Commission gave consent for the use of laboratory animals for the experiments (Marmara University, 24.03.2008-13.03.2008).

\section{PRP preparation}

The PRP was prepared using RegenKit THT Autologous Platelet-Rich Plasma (A-PRP) (RegenKit ${ }^{\circledR}$ THT, Stryker, Kalamazoo, USA), which is a PRP preparation with high platelet recovery and viability, physiological levels of leukocytes, and the entire plasma component of blood rich in growth factors.

All animals were anesthetized using $100 \mathrm{mg} / \mathrm{kg}$ intraperitoneal ketamine hydrochloride plus $3-5 \mathrm{mg} / \mathrm{kg}$ chlorpromazine. Eight milliliters of blood was collected from the marginal ear vein of the rabbits under strict aseptic conditions. The blood samples were transferred to a Regen THT tube that had thixotropic gel to separate the red blood cells from the whole blood. The samples were then centrifuged for $8 \mathrm{~min}$ at $3400 \mathrm{rpm}$, and PRP was extracted using the syringe.

\section{Surgical procedure}

After the blood samples were taken, a preoperative dose of intramuscular cefazolin sodium $(0.1 \mathrm{mg} / \mathrm{kg})$ was given for prophylaxis against infection. After the posterior side of the right ankle of the rabbits was shaved and before sterile covering, povidone iodine was used for prepping. Cutaneous and subcutaneous incisions were made over the Achilles tendon; $3 \mathrm{~cm}$ of the tendon was cut off from the insertion to the calcaneus and proximal musculotendinous part. The 2 ends of the graft were sutured with $2 / 0$ vicryl using the Krackow technique, and the thicknesses of the tendons were measured.

The prepared tendons were covered in a wet gauge. Later the distal parts of both femurs were shaved and covered with sterile drapes. An approximately 2 -cm incision was made anterior to the distal aspect of the right femur. After advancing through the skin and subcutaneous layers, the quadriceps was deviated laterally to reach the bone. After incising the periosteum, it was detached to the posterolateral aspect of the femur. Using a K-wire, a 1-cm deep tunnel was drilled with an appropriate-thickness (as the graft thickness) cannulated drill (Fig. 1). After the tunnel preparation, the tunnel was filled with PRP so that the graft was totally covered with PRP as it advanced into the tunnel. The graft was sutured to the posteromedial periosteum at the point where it exited the tunnel. The PRP was again applied inside the tunnel (Fig. 2). Later all the layers, skin, and subcutaneous tissue were closed in the appropriate order and a dressing was applied to the wounds. In the control group (left femurs), except for the PRP application, all other procedures were performed in the same manner.

\section{Postoperative care}

In the postoperative period, intramuscular cefazolin sodium $0.1 \mathrm{mg} / \mathrm{kg}$ was administered for 5 days for antibiotic prophylaxis. Every 3 days, the dressing was applied on both the incision areas. After 10 days, the sutures were removed. On the $56^{\text {th }}$ day postoperatively, the portion of the distal femur containing the tunnel was amputated for histological evaluation. 


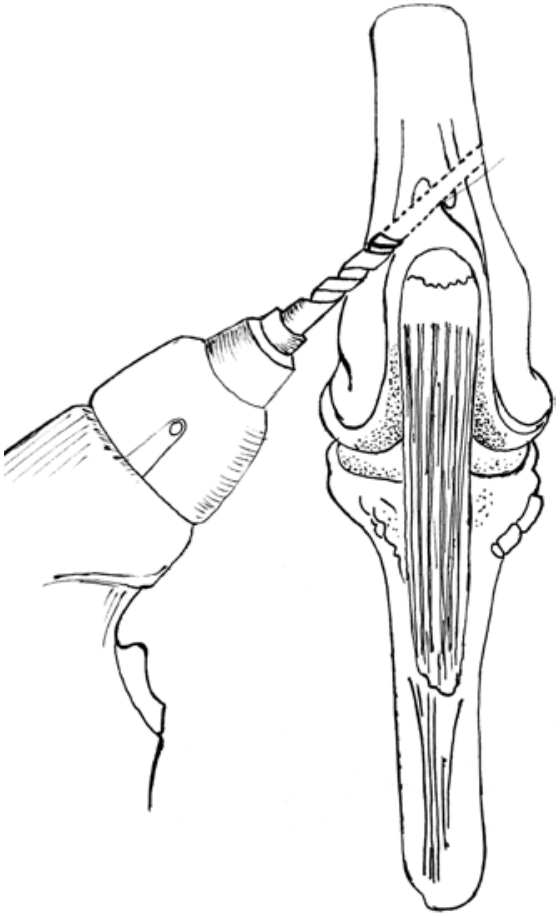

Fig. 1. Diagram showing the direction of the femoral tunnel

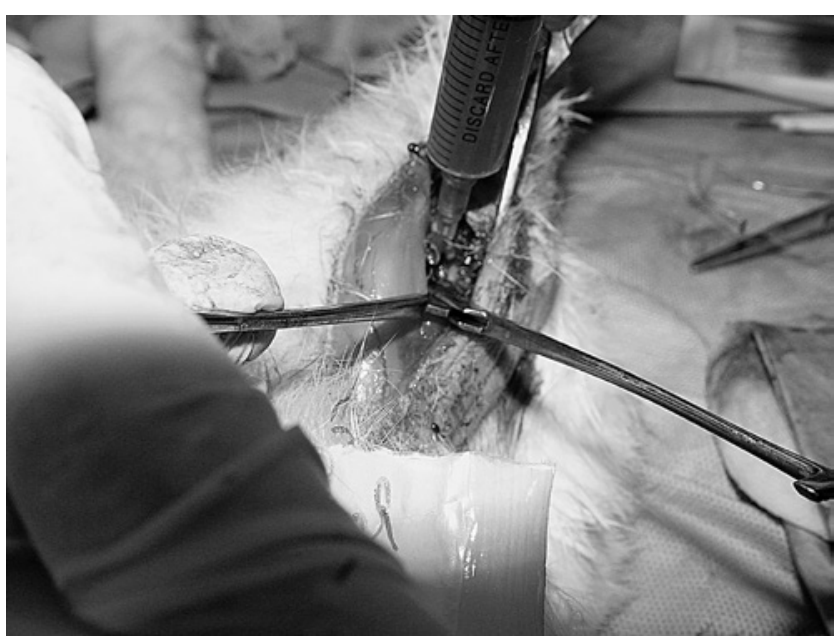

Fig. 2. PRP injected into the tunnel after the tendon was fixed

\section{Preparation for microscopy}

For light microscopy, the tissue samples were fixed in $10 \%$ buffered formalin for $48 \mathrm{~h}$, dehydrated in ascending alcohol series, and embedded in paraffin wax. Approximately $7-\mu \mathrm{m}$-thick sections were stained with Masson's trichrome stain to demonstrate the general morphology.

\section{Results}

The histological evaluation revealed that the tendonbone integration was successful in most of the tissues without any necrosis (Figs. 3Ra, Rb). Inflammatory cellu-
Table 1. Histologic scorin g (semi-quantitative histologic analysis)

\begin{tabular}{|c|c|c|}
\hline $\begin{array}{l}\text { Histological findings with } \\
\text { Masson's Trichrome stain }\end{array}$ & $\begin{array}{l}\text { Study group } \\
\text { (10 right knees) }\end{array}$ & $\begin{array}{l}\text { Control group } \\
\text { (10 left knees) }\end{array}$ \\
\hline Cellularity & + & +++ \\
\hline $\begin{array}{l}\text { Morphologic disorganization } \\
\text { in integration }\end{array}$ & - & +++ \\
\hline Edema & - & +++ \\
\hline Tendon layout & - & +++ \\
\hline
\end{tabular}

Each parameter displays: $(-)$ none, $(+)$ mild $(++)$ moderate, or $(+++)$ severe. Masson's Trichrome stain. $\times 100$ and ×200 (insets).

larity in the integration zones was less in the study group compared to the control group. However, in the control group (Figs. 4La, Lb), the integration was distorted in many zones and some cystic morphologies were present (Table 1).

\section{Discussion}

Autologous bone-patellar tendon-bone graft offers the strongest healing potential because it relies mainly on bone-to-bone integration between the graft bone plug and the tunnel wall. ${ }^{10}$ However, it has some donor-site morbidity, which has led surgeons to search for alternative graft sources. Hamstring grafts are the most used alternative. These grafts have less donor-site morbidity, but the initial bone-tendon attachment is weaker than the bone-bone attachment, which limits rehabilitation and delays return to activity. ${ }^{10}$ Hamstring grafts also have a slower rate of healing. ${ }^{11,12}$ Hence, there was a need to look for ways to improve the bone-tendon healing, which was thought to be multifactorial, involving biomechanical and biological factors..$^{13} \mathrm{New}$ fixation materials have been developed recently for more stable biomechanical bonetendon fixation. ${ }^{14}$ However, these materials are functional only before tissue healing occurs.

The long-term success of an ACL reconstruction depends on adequate graft healing into a bone tunnel. ${ }^{15}$ For this reason, researchers have focused more on increasing integration using growth factors. Strategies to improve tendon-bone tunnel healing have focused on providing appropriate molecular signals and cell differentiation resulting in an effective healing response between tendon and bone. ${ }^{16}$ Some studies have been demonstrated to improve bone ingrowth into a tendon graft placed in a bone tunnel with the use of osteoinductive cytokines. ${ }^{16-19}$ Hyperbaric oxygen, low intensity pulsed ultrasound and extracorporeal shock waves could induce marked increases in vascularity, which improve new bone formation. ${ }^{16,20,21}$ Osteoconductive materials may also play a role in improving tendon healing in a bone tunnel via enriched bone ingrowth. . $^{16,18,20}$ $\mathrm{Chen} \mathrm{CH}$ et al. evaluated the effect of a periosteum-enveloping tendon graft on tendon-bone healing in 2 different experimental models in rabbits and they concluded that 

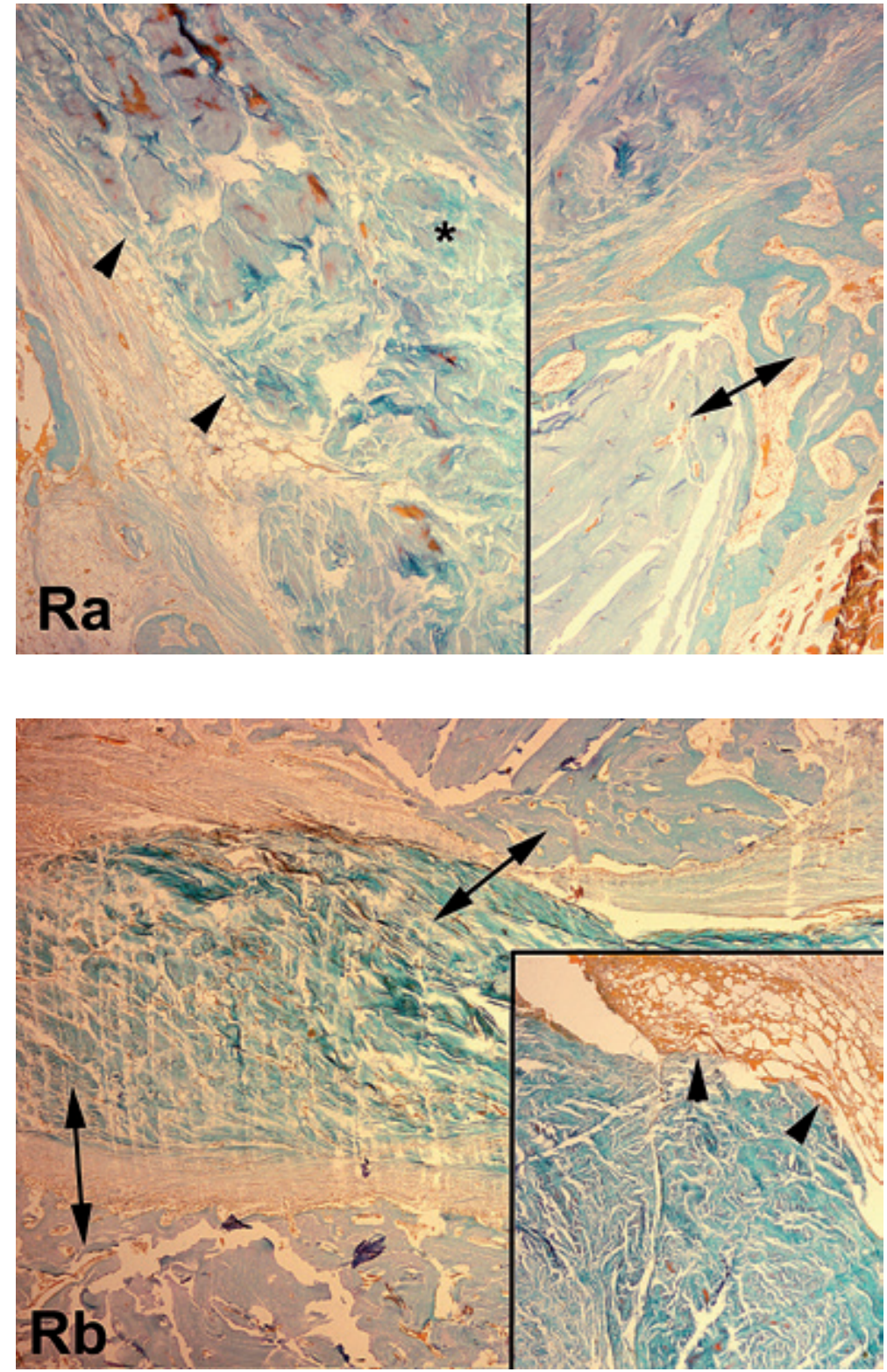

Fig. 3Ra. Integration zones of the tendon in bone (doubleheaded arrow); tendon integration points with connective tissue in periphery the (arrowheads); $\left(^{*}\right)$ indicates the tendon; $\mathrm{Ra}$ - right knee (study group) Fig. a
Fig. 3Rb. Integration of the tendon in bone tissue without any edema (double-headed arrows); the nidus of tendon integration (arrows); $\mathrm{Rb}$ - right knee (study group) Fig. b a superior healing process and stronger healing strength could be achieved when the periosteum was sutured on the tendon graft inserted into a bone tunnel. ${ }^{22,23} \mathrm{Chen} \mathrm{CH}$ et al. also evaluated the periosteal progenitor cells (PPC)BMP-2 hydrogel for tendon-bone healing in 2 different experimental models and they concluded that PPC-BMP-2 is a powerful inducer of tendon-bone healing through the neoformation of fibrocartilage. ${ }^{24,25}$

PRP is rich in growth factors and proteins, such as fibrinogen. ${ }^{26-28}$ The growth factors play an important role in the regulation of growth and development of a variety of tissues. ${ }^{29}$ They accelerate the wound healing processes by increasing cellular proliferation, matrix formation, osteoid production, connective tissue healing, angiogenesis, and collagen synthesis. ${ }^{30}$ PRP contains plateletderived growth factor (PDGF), transforming growth factor beta 1 (TGF- $\beta 1$ ), platelet-derived epidermal growth factor (PDEGF), platelet-derived angiogenesis factor
(PDAF), insulin-like growth factor 1 (IGF-1), platelet factor 4 (PF-4), vascular endothelial growth factor (VEGF), fibroblast-derived growth factor (FGF), epidermal growth factor (EGF), and bioadhesive proteins such as fibrinogen, fibronectin, and vitronectin. ${ }^{31,32}$

There is no consensus regarding the use of growth factors in ACL surgery. ${ }^{1,33,34}$ The structure of the ACL becomes tendon-like 9-12 months after surgery. Ventura et al. observed that the transformation from autologous quadrupled hamstring tendon graft (QHTG) to new ACL was faster in the PRP-treated group than in the controls. Hence, it was assumed that the growth factors, which were obtained using the Biomet-Merck Gravitational Platelet Separation (GPS) technique and applied to the femoral and tibial tunnels during the surgery, could accelerate the integration of the new ACL in the femoral and tibial tunnels. Computed tomography $(\mathrm{CT})$ data confirmed this hypothesis. ${ }^{1}$ In a study by Vogrin et al., PRP was applied to the femoral 

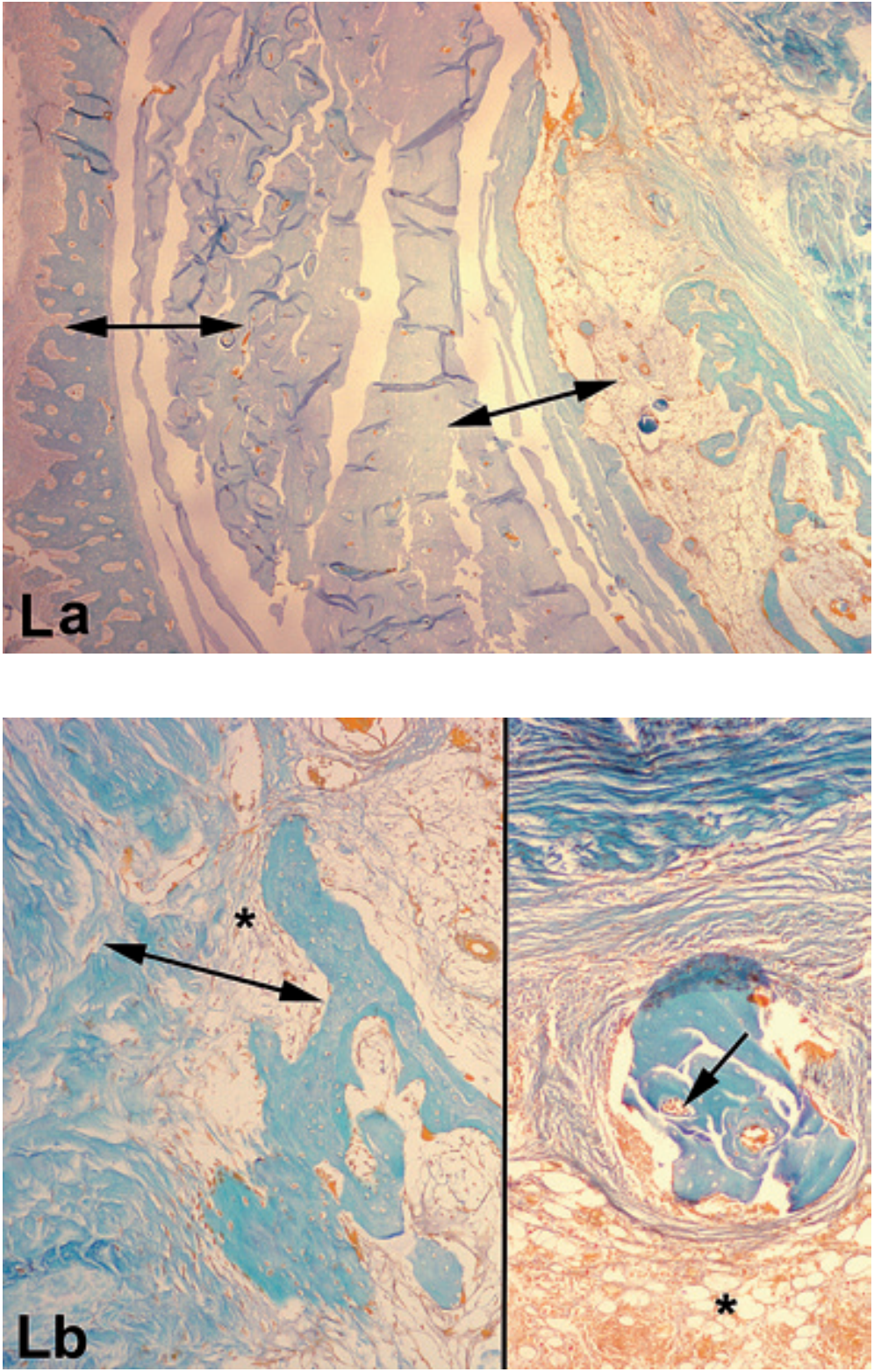

Fig. 4La. The edemateous interval between the bone and the tendon (double-headed arrows) where the integration is not proper; La - left knee (control group) Fig. a and tibial tunnels as well as on the graft itself after autograft reposition. ${ }^{35}$ Contrast-enhanced magnetic resonance imaging (MRI) studies were performed 4-6 and 10-12 weeks after the surgery. After 4-6 weeks, the PRP-treated group demonstrated a significantly higher level of vascularization in the osteoligamentous interface compared to the control group. It was concluded that locally applied PRP enhanced early revascularization of the graft in the osteoligamentous interface zone after ACL reconstruction. In a 2010 study by Silva et al., the patients were sequentially enrolled into 4 groups: Group A without PRP; group B with PRP in the femoral tunnels at the end of the surgery; group $C$ with PRP in the femoral tunnels at the end of the surgery and intraarticularly 2 and 4 weeks after the surgery; and group D with PRP activated with thrombin in the femoral tunnels. ${ }^{13}$ All patients underwent MRI of the knee 3 months after the surgery to evaluate the signal intensity of the fibrous interzone in the femoral tunnels. However, no difference was found among the groups when comparing the signal intensity of the fibrous interzone on MRI.

The results of the aforementioned studies were consistent with the radiological findings. However, histological findings are more reliable than CT and Magnetic Resonance Imaging (MRI) findings because bone-tendon integration is a biological phenomenon. The molecular findings are difficult to demonstrate with CT or MRI. In the present study, PRP was applied to the femoral tunnel after Achilles tendon graft reposition. After 8 weeks, bone-tendon integration was studied histologically. The bone-tendon integration in most of the tissues was successful without any necrosis in the study group. Also, inflammatory cellularity was less in the study group compared to the control group. However, the integration was distorted in many zones and some cystic morphologies were present in the control group. These findings indicate improved bone-tendon integration using PRP. 
Browning et al. found that PRP contains a mixture of anabolic and catabolic mediators. Synoviocytes treated with platelet-rich plasma responded with secretion of matrix metalloproteinases, which might increase cartilage catabolism. ${ }^{36}$ However, similar results were found in the study by Demirag et al. using alpha-2-macroglobulin. ${ }^{11}$ Bilateral ACL reconstruction was performed with the use of the ipsilateral semitendinosus tendon in rabbits. Alpha-2-macroglobulin was injected into the knee joint in one limb, and the contralateral limb served as a control. Their results demonstrated that alpha-2-macroglobulin blockade of matrix metalloproteinases can enhance bone-tendon healing. Consequently, PRP and alpha-2-macroglobulin injection during the same procedure may increase the effect of PRP on bone-tendon integration.

Another issue regarding the growth factors in PRP is the varying effects of different growth factors of the same pool. Platelet sequestration results in a platelet concentrate that, upon activation, releases a cascade of growth factors contained in the alpha granules. The growth factors released from the platelets signal the local mesenchymal cells and epithelial cells to migrate, divide, and increase collagen and matrix formation. Each growth factors can be studied to distinguish their effects on bonetendon integration by means of their biomechanical and histological properties. Some growth factors may have a negative influence on bone-tendon integration according to the study results, so extracting these growth factors may improve bone-tendon integration.

A limitation of this study was that it lacked biomechanical tests, extra-articular fixation, and tendon fixation techniques. Bone-tendon integration was also affected by intra-articular materials during healing, however this was fixed extra-articularly. The graft was sutured to the periosteum. It is not a strong fixation technique compared to other fixation techniques that are used in ACL surgeries. This might have affected the results of the present study results negatively.

PRP was used as a source of growth factors in this study and tendon graft integration was evaluated histologically. The bone-tendon integration was successful without any necrosis in the study group. The histological findings will be more reliable with radiological findings. However, the biomechanical properties of this integration still need to be explored.

\section{References}

1. Ventura A, Terzaghi C, Borgo E, Verdoia C, Gallazzi M, Failoni S. Use of growth factors in ACL surgery: Preliminary study. J Orthop Traumatol. 2005;6:76-79.

2. Ferrari JD, Bach BR. Isolated anterior cruciate ligament injury. In: Chapman MW, ed. Chapman's Orthopaedic Surgery. Philadelphia, PA: Lippincott, Williams and Wilkins; 2001:2347-2359.

3. Hamner DL, Brown CH Jr, Steiner ME, et al. Hamstring tendon grafts for reconstruction of the anterior cruciate ligament: Biomechanical evaluation of the use of multiple strands and tensioning techniques. J Bone Joint Surg Am. 1999;81:549-557.
4. Kurosaka M, Yoshiya S, Andrish JT. A biomechanical comparison of different surgical techniques of graft fixation in anterior cruciate ligament reconstruction. Am J Sports Med. 1987;15:225-229.

5. Martinek V, Latterman C, Usas A, et al. Enhancement of tendonbone integration of anterior cruciate ligament grafts with bone morphogenetic protein-2 gene transfer: A histological and biomechanical study. J Bone Joint Surg Am. 2002;84:1123-1131.

6. Rodeo SA, Arnoczky SP, Torzilli PA, Hidaka C, Warren RF. Tendonhealing in a bone tunnel: A biomechanical and histological study in the dog. J Bone Joint Surg Am. 1993;75:1795-1803.

7. Gibble J, Ness P. Fibrin glue: The perfect operative sealant? Transfusion. 1990;30:741-747.

8. Hood AG, Hill AG, Reeder GD. Perioperative autologous sequestration. III: A new physiologic glue with wound healing properties. Proc Am Acad Cardiovasc Perfusion. 1993;14:126-130.

9. Marx RE, Carlson ER, Eichstaedt RM, Schimmele SR, Strauss JE, Georgeff KR. Platelet-rich plasma: Growth factor enhancement for bone grafts. Oral Surg Oral Med Oral Pathol Oral Radiol Endod. 1998; 85:638-646.

10. Silva A, Sampaio R. Anatomic ACL reconstruction: Does the platelet-rich plasma accelerate tendon healing? Knee Surg Sports Traumatol Arthrosc. 2009;17:676-682.

11. Demirag B, Sarisozen B, Ozer O, Kaplan T, Ozturk C. Enhancement of tendon-bone healing of anterior cruciate ligament grafts by blockage of matrix metalloproteinases. J Bone Joint Surg Am. 2005;87:2401-2410.

12. Kyung HS, Kim SY, Oh CW, Kim SJ. Tendon-to-bone tunnel healing in a rabbit model: The effect of periosteum augmentation at the tendon-to-bone interface. Knee Surg Sports Traumatol Arthrosc. 2003;11:9-15.

13. Silva A, Sampaio R, Pinto E. Femoral tunnel enlargement after anatomic ACL reconstruction: A biological problem? Knee Surg Sports Traumatol Arthrosc. 2010;18:1189-1194.

14. Weiler A, Hoffmann RF, Stähelin AC, Bail HJ, Siepe CJ, Südkamp NP. Hamstring tendon fixation using interference screws: A biomechanical study in calftibial bone. Arthroscopy. 1998;14:29-37.

15. Bachy M, Sherifi I, Zadegân F, Petrover D, Petite H, Hannouche D. Anterior cruciate ligament surgery in the rabbit. J Orthop Surg Res. 2013;19:8-27.

16. Chih-Hwa Chen. Strategies to enhance tendon graft-bone healing in Anterior Cruciate Ligament reconstruction. Chang Gung Med J. 2009;32:483-493.

17. Yamazaki S, Yasuda K, Tomita F, Tohyama H, Minami A. The effect of transforming growth factor-beta1 on intraosseous healing of flexor tendon autograft replacement of anterior cruciate ligament in dogs. Arthroscopy. 2005;21:1034-1041.

18. Gulotta LV, Kovacevic D, Ying L, Ehteshami JR, Montgomery S, Rodeo SA. Augmentation of tendon-to bone healing with a magnesium-based bone adhesive. Am J Sports Med. 2008;36, 1290-1297.

19. Rodeo SA, Suzuki K, Deng XH, Wozney J, Warren RF. Use of recombinant human bone morphogenetic protein-2 to enhance tendon healing in a bone tunnel. Am J Sports Med. 1999;27:476-488.

20. Walsh WR, Stephens P, Vizesi F, Bruce W, Huckle J, Yu Y. Effects of low-intensity pulsed ultrasound on tendon bone healing in an intra-articular sheep knee model. Arthroscopy. 2007;23:197-204.

21. Wang CJ, Wang FS, Yang KD, Weng LH, Sun YC, Yang YJ. The effect of shock wave treatment at the tendonbone interface: A histomorphological and biomechanical study in rabbits. J Orthop Res. 2005;23:274-280

22. Chen $\mathrm{CH}$, Chen WJ, Shih $\mathrm{CH}$. Enveloping of periosteum on the tendon graft to enhance tendon-bone healing in a bone tunnel: A biomechanical and histological studies in rabbits. Arthroscopy. 2003;19:290-296.

23. Chen $\mathrm{CH}$, Chen $\mathrm{LH}$, Chen WJ, et al. Periosteum-enveloping of the tendon to enhance tendon-bone healing in the bone tunnel: Histologic studies in three experimental rabbit models. J Orthop Surg Taiwan. 2003;20:21-29.

24. Chen CH, Liu HW, Tsai CL, Yu CM, Lin IH, Hsiue GH. Photoencapsulation of bone morphogenetic protein-2 and Periosteal progenitor cells improve tendon graft healing in a bone tunnel. Am J Sports Med. 2008;36:461-473. 
25. Chen $\mathrm{CH}$, Liu HW, Hsiue GH, Tsai CL, Yu CM, Lin IH. Photoencapsulation of bone morphogenetic protein-2 and Periosteal progenitor cells enhance tendon-bone healing in anterior cruciate ligament reconstruction. Trans Orthop Res Soc. 2008;33:255.

26. Cieślik-Bielecka A, Bielecki T, Gaździk TS, Arendt J, Król W, Szczepański T. Autologous platelets and leukocytes can improve healing of infected high-energy soft tissue injury. Transfus Apher Sci. 2009;41:9-12.

27. Clark RA. Fibrin and Wound Healing. Ann N Y Acad Sci. 2001;936:355367.

28. Whitman DH, Berry RL, Green DM. Platelet gel: An autologous alternative to fibrin glue with applications in oral and maxillofacial surgery. J Oral Maxillofac Surg. 1997;55:1294-1299.

29. Mishra A, Woodall J Jr, Vieira A. Treatment of tendon and muscle using platelet-rich plasma. Clin Sports Med. 2009;28:113-125.

30. Rick GS, Craig JG, Mark SC. Platelet-rich plasma: Properties and clinical applications. J Lancaster Gen Hosp. 2007;2:73-77.
31. Ganio C, Tenewitz FE, Wilson RC, Maules BG. The treatment of chronic nonhealing wounds using autologous platelet-derived growth factors. J Foot Ankle Surg. 1993;32:263-268.

32. Paoloni J, De Vos RJ, Hamilton B, Murrell GA, Orchard J. Platelet-rich plasma treatment for ligament and tendon injuries. Clin J Sport Med. 2011;21:37-45.

33. Schmidt CC, Georgescu HI, Kwoh CK, et al. Effect of growth factors on the proliferation of fibroblasts from the medial collateral and anterior cruciate ligaments. J Orthop Res. 1995;13:184-190.

34. Yoshida M, Fuji K. Differences in cellular properties and responses to growth factors between human ACL and MCL cells. J Orthop Sci. 1999;4:293-298.

35. Vogrin M, Rupreht M, Dinevski D, et al. Effects of a platelet gel on early graft revascularization after anterior cruciate ligament reconstruction: A prospective, randomized, double-blind, clinical trial. Eur Surg Res. 2010;45:77-85.

36. Browning SR, Weiser AM, Woolf $\mathrm{N}$, et al. Platelet-rich plasma increases matrix metalloproteinases in cultures of human synovial fibroblasts. J Bone Joint Surg Am. 2012;5:1721-1727. 